\title{
Thermal Diffusivity of Iron at High Temperature in Both the Liquid and Solid States
}

\author{
B. J. MONAGHAN and P. N. QUESTED ${ }^{11}$
}

Formerly at Materials Centre, National Physical Laboratory, Teddington, Middlesex, TW11 OLW, UK. Now at Department of Materials Engineering, University of Wollongong, Wollongong, NSW 2522 Australia. E-mail: brian_monaghan@nsw.edu.ac 1) Materials Centre, National Physical Laboratory, Teddington, Middlesex, TW11 OLW, UK. E-mail: peter.quested@npl.co.uk

(Received on May 7, 2001; accepted in final form on September 3, 2001)

\begin{abstract}
Thermal diffusivity measurements of pure iron have been made using a laser flash apparatus (LFA) over the temperature range 25 to $1640^{\circ} \mathrm{C}$. These measurements are compared with existing data and recommended values are given. In the $\gamma$-Fe phase region the thermal diffusivity can be represented by $a=6 \times 10^{-6}+3.13 \times 10^{-9} \times(T-911)$. In the $\delta$-Fe phase region the thermal diffusivity can be represented by the constant $0.07 \times 10^{-4} \mathrm{~m}^{2} \mathrm{~s}^{-1}$. In the liquid region up to $1640^{\circ} \mathrm{C}$, the thermal diffusivity can be represented by $a=6.2 \times 10^{-6}+1.79 \times 10^{-9} \times(T-1538)$. $T$ in both equations is temperature in Celsius and the thermal diffusivity equation units are $\mathrm{m}^{2} \mathrm{~s}^{-1}$.

To improve the LFA measurement characteristics of a metal, it is often coated with graphite. Unfortunately, due to the solubility of carbon in iron, at high temperatures, the coating does not remain on the surface of the iron. The effect of using a zirconia coating as opposed to a graphite coating was tested. The efficacy of this change was evaluated by comparing thermal diffusivity measurements on Cu using both coating materials.
\end{abstract}

KEY WORDS: thermal diffusivity; solid and liquid states of iron; laser flash method; metal processing.

\section{Introduction}

Process models that simulate industrial processes are increasingly being used to reduce costs and improve productivity. ${ }^{1-8)}$ The success of such models is highly dependent on the thermophysical property data used in the simulation calculations. Unfortunately high temperature thermophysical data for liquid metals and slags are scarce. Also what data that are available often have a high uncertainty associated with them. ${ }^{1,2,9-11)}$ Therefore regardless of how well a process model may be physically based it is likely, given the current state of high temperature thermophysical property data, in particular heat capacity, viscosity and thermal conductivity/diffusivity, that the models predictions will be limited by the uncertainty associated with the data. It is unclear how much such models are being used by industry but extreme care should be exercised when attempting to realise or understand the predictions of process simulation models.

At the National Physical Laboratory we have attempted to address some of the problems associated with the measurement of thermophysical properties at high temperatures. This paper outlines the developments we have made in the measurement of the thermal diffusivity of liquid metals by use of a laser flash technique and presents our recent measurements on pure iron.

Thermal conductivities/diffusivities of liquid metals are difficult to measure. These difficulties are a result of the following:

a) Chemical reactivity (containment) problems at high temperatures required for metallic systems

b) Convectional (mass flow) heat transfer of the liquid. It is difficult to hold liquid metal at high temperatures and make thermal-conductivity/diffusivity measurements without there being a convectional term associated with the measured value, as thermal instabilities in the measurement systems can be enough to initiate convection.

There is a further problem associated with laser flash thermal diffusivity measurements of liquid iron. Classical laser flash measurements often require the sample to be covered with graphite to improve the signal to noise ratio of the measurement. ${ }^{12)}$ This is not possible with pure liquid iron and steel as they have a significant Carbon solubility. ${ }^{13)}$

Given the problems associated with the laser flash technique for making measurement on liquid iron, the approach to develop the technique for the measurement of iron could be questioned. The reason for this approach can be found in the review of the thermal conductivities/diffusivities of liquid metals carried out by Mills et al. ${ }^{2)}$ The review found that that the laser flash technique seemed to be one of two techniques currently available capable of making thermal diffusivity measurements in the liquid at the high temperatures required for steelmaking. The other was Zinovyev's electron beam technique. ${ }^{14)}$ It was felt that Zinovyev's technique $^{14)}$ did not lend itself to the development of a laborato- 


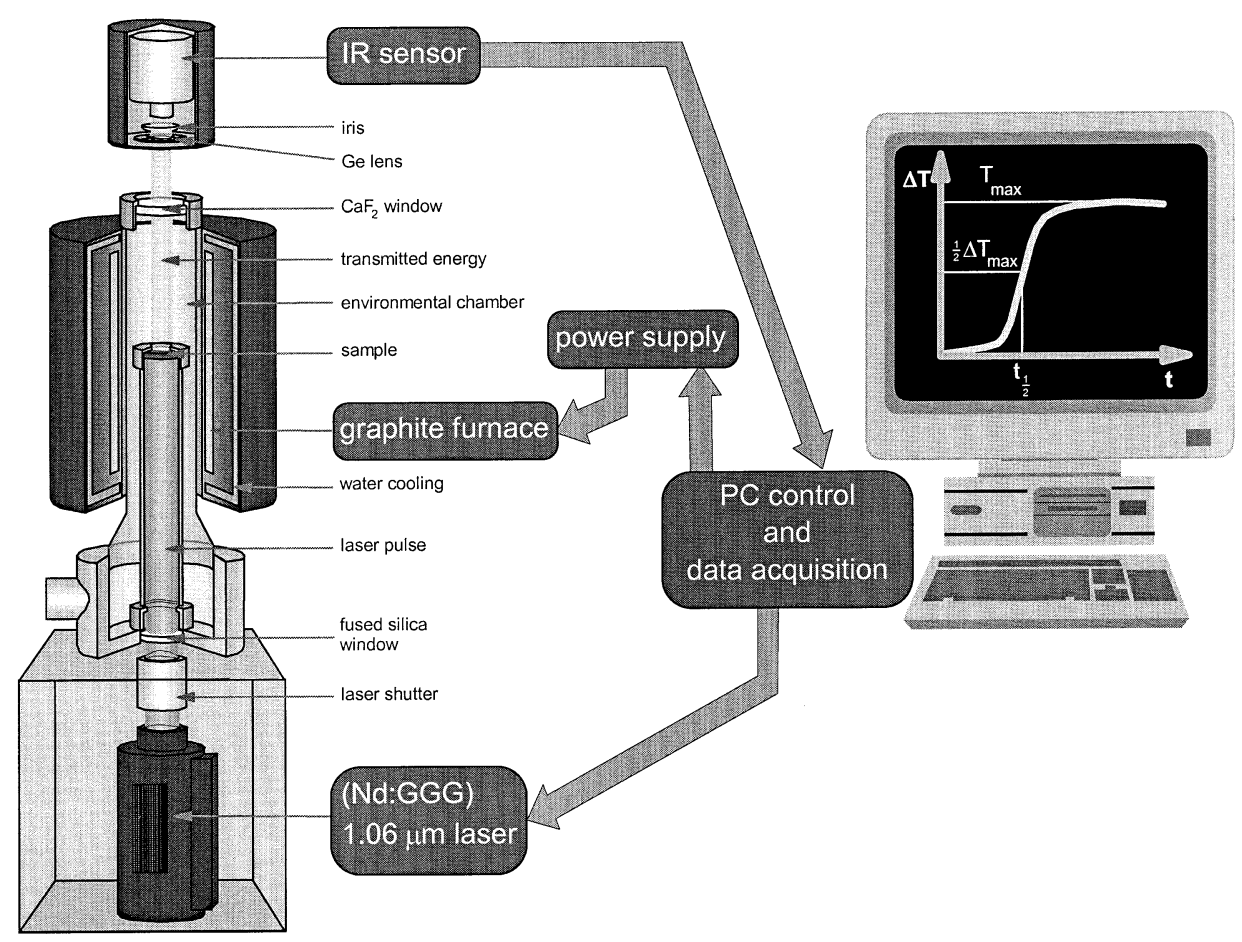

Fig. 1. Schematic of the laser flash apparatus.

ry bench apparatus. Therefore the laser flash technique was chosen for further development.

The principle advantages of the laser flash method for the measurement of thermal diffusivity are

- it is a semi contact measurement technique. A probe is not inserted in the melt to make a measurement; both the laser and measurement sensor are remote from the melt. Therefore, the only contact with the molten metal is the holding container, thereby minimising the effects of contamination of the melt.

- the measurement is very fast, $<0.5$ of a second for a complete measurement. Such a fast measurement technique minimises the errors associated with convection.

\section{Experimental}

\subsection{Laser Flash Apparatus}

The thermal diffusivities presented in this paper were measured using a Netzsch 427 laser flash apparatus (LFA). A schematic of the LFA is given in Fig. 1.

It is a standard piece of equipment, the details of which are published elsewhere. ${ }^{12,15)}$ The measurement involves heating the front face of a disc-shaped sample using a high intensity laser and monitoring the temperature rise on the back face. From the temperature rise, the thermal diffusivity $(a)$ can be calculated by Eq. (1), ${ }^{15)}$

$$
a=\frac{1.37 \times l}{\pi^{2} t_{0.5}}
$$

where $l$ is the thickness of the sample $t_{0.5}$ is the time taken for the temperature rise to reach half the value of the maximum temperature rise. Eq. (1) represents ideal adiabatic conditions for an idealized instantaneous energy pulse. Corrections can be made for heat loss effects and the finite pulse time of the laser. ${ }^{16)}$ The sample may be sprayed with graphite or zirconia prior to placing in the LFA and measurements are made in an argon atmosphere. The method has an estimated uncertainty of $\pm 5 \%$ for solids. ${ }^{1)}$ The laser flash method is well developed for solids but has only relatively recently been applied to liquid metal measurement. $^{17-20)}$

In liquid measurements the sample is held in a sapphire cell a schematic of which is given in Fig. 2.

The sapphire cell is transparent to the laser (wavelength $1.064 \mu \mathrm{m}$ ) and UV light and to all intents and purposes can be ignored with respect to the thermal diffusivity measurement. The materials used in this study are given in Table $\mathbf{1}$.

\subsection{Validation of the Zirconia Coating}

Zirconia was chosen to coat the sample because it was readily available in paint form and is chemically stable with respect to iron at high temperatures. Also preliminary tests demonstrated that it did improve the signal to noise ratio of measurements made in the LFA. ${ }^{21)}$ What was not clear was how the zirconia coating effects the measured thermal diffusivity.

To assess the effects of the zirconia coating on the measured thermal diffusivity measurements were made on zirconia coated electrolytic copper and compared with measurements made on graphite coated electrolytic copper. The results of a number of measurement runs are shown in Fig. 3.

Also plotted on Fig. 3 are the recommended thermal diffusivities values for pure copper in the solid state from Touloukian's thermophysical property review. ${ }^{22)}$ On inspection of Fig. 3 it can be seen that the graphite coated samples are in good agreement with the recommended values. Below $650^{\circ} \mathrm{C}$ the zirconia coated $\mathrm{Cu}$ sample has a measured thermal diffusivity lower than both that of the graphite coated $\mathrm{Cu}$ and the Touloukian's recommended values. Above $650^{\circ} \mathrm{C}$ there is extremely good agreement be- 


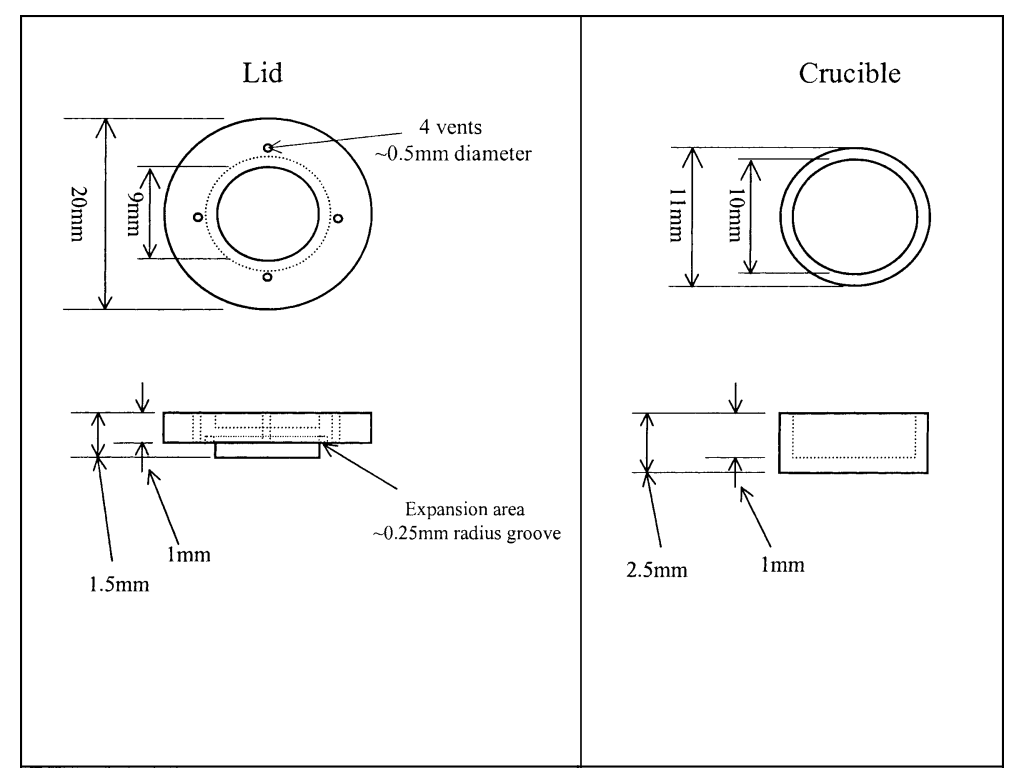

Fig. 2. Schematic of the sapphire cell.

Table 1. Sample identification and composition.

\begin{tabular}{|c|c|c|c|c|c|}
\hline \hline \multirow{2}{*}{$\begin{array}{l}\text { NPL } \\
\text { identifier }\end{array}$} & Material & \multicolumn{4}{|c|}{ Composition (wt\%) } \\
\cline { 3 - 6 } & & Parent & $\mathrm{C}$ & $\mathrm{S}$ & Other \\
\hline $\mathrm{CGQ}$ & $\begin{array}{c}\text { Electrolytic } \\
\mathrm{Cu}\end{array}$ & 99.98 & $/$ & $/$ & $/$ \\
\hline $\mathrm{ACF}$ & Pure Fe & Balance & 0.011 & 0.005 & $*$ \\
\hline
\end{tabular}

${ }^{*} \mathrm{Si}, \mathrm{Mn}, \mathrm{P}, \mathrm{Cr}, \mathrm{Mo}, \mathrm{Ni}, \mathrm{Cu}, \mathrm{Sn}, \mathrm{V}$ and $\mathrm{Co}$ were analyzed using ICP and all had compositions less than the instruments detection limit of $0.002 \mathrm{wt} \%$. The analysis was carried out by CORUS (formerly British Steel plc) at their Teesside Technical Centre in the UK.

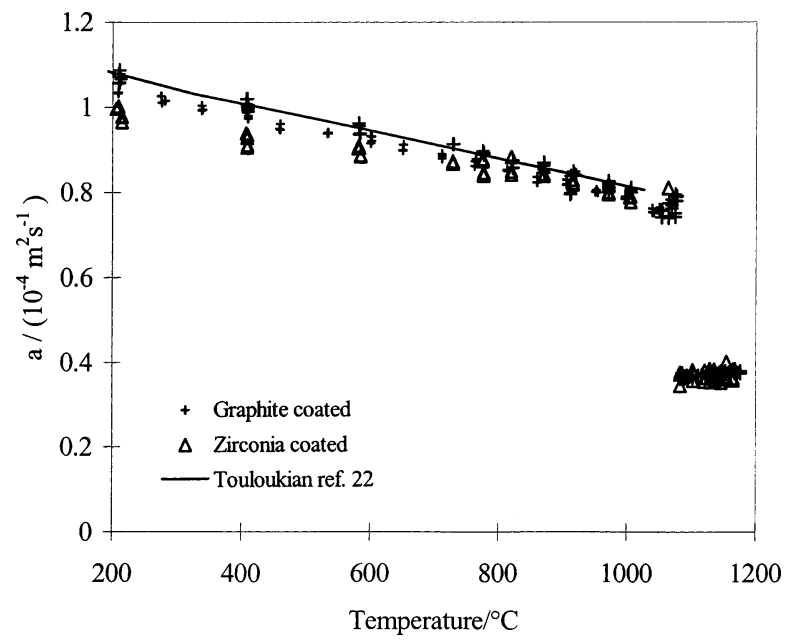

Fig. 3. Change of thermal diffusivity with temperature of copper with different coatings.

tween all sets of data. This result indicates that above approximately $650^{\circ} \mathrm{C}$ the zirconia coating is not interfering with the laser flash thermal diffusivity measurement.

It is believed that this behaviour can be explained in terms of the radiation transmission properties of the material zirconia. At temperatures below $650^{\circ} \mathrm{C}$, the heat conduction properties of the zirconia are dominated by the relatively slow lattice (phonon) conductivity but above $650^{\circ} \mathrm{C}$ radiation (photon) conduction is dominant. The zirconia coating thickness, measured using a high-resolution optical microscope and calibrated graticule, was 26 microns. This thickness can be considered optically thin for zirconia and as such cause little interference to the heat transfer through the zirconia coated sample. ${ }^{23)}$

\section{Results and Discussion}

Figure 4 shows the results of thermal diffusivity measurements on pure iron ACF. These data are compared with Touloukian's ${ }^{24)}$ recommended values for pure iron and Zinovyev et al.'s ${ }^{14,26,27)}$ data. In the authors knowledge Zinovyev et $a l^{14,26,27)}$ are the only other researchers that have made thermal diffusivity measurement at temperatures near the melting point or in the liquid phase region of iron. The solid sample geometry for the ACF iron was corrected for expansion using linear expansion coefficients based on the recommended values given in TPRL series ${ }^{27)}$ and those measured by Waseda et al. ${ }^{28)}$ The linear expansion coefficients used are given in Table 2.

The sapphire cell defines the sample geometry in the liquid phase. The expansion of the sapphire cell was corrected using Eq. (2), ${ }^{29)}$

$$
\begin{aligned}
\frac{\Delta l}{l_{\mathrm{o}}}= & -0.180+5.494 \times 10^{-4}(T+273.15) \\
& +2.252 \times 10^{-7}(T+273.15)^{2} \\
& -2.894 \times 10^{-11}(T+273.15)^{3} \ldots \ldots \ldots \ldots \ldots
\end{aligned}
$$

where $l_{\mathrm{O}}$ is the measured thickness of the cell at ambient temperature, $\Delta l$ the change in thickness on increasing temperature and $T$ is temperature in Celsius. The different ACF numbers on Fig. 4 denote different sample of the same material. Also letters H, C, G and Z denote heating, cooling, graphite coated and zirconia coated respectively.

It can be seen in Fig. 4, that where comparisons can be made, the thermal diffusivity measured in this study on pure iron (ACF) is in good agreement with that recommended by Touloukian. ${ }^{24}$ The Touloukian values are based on over 100 data sets available prior to the book being published. There is a difference between the Touloukian ${ }^{24)}$ rec- 


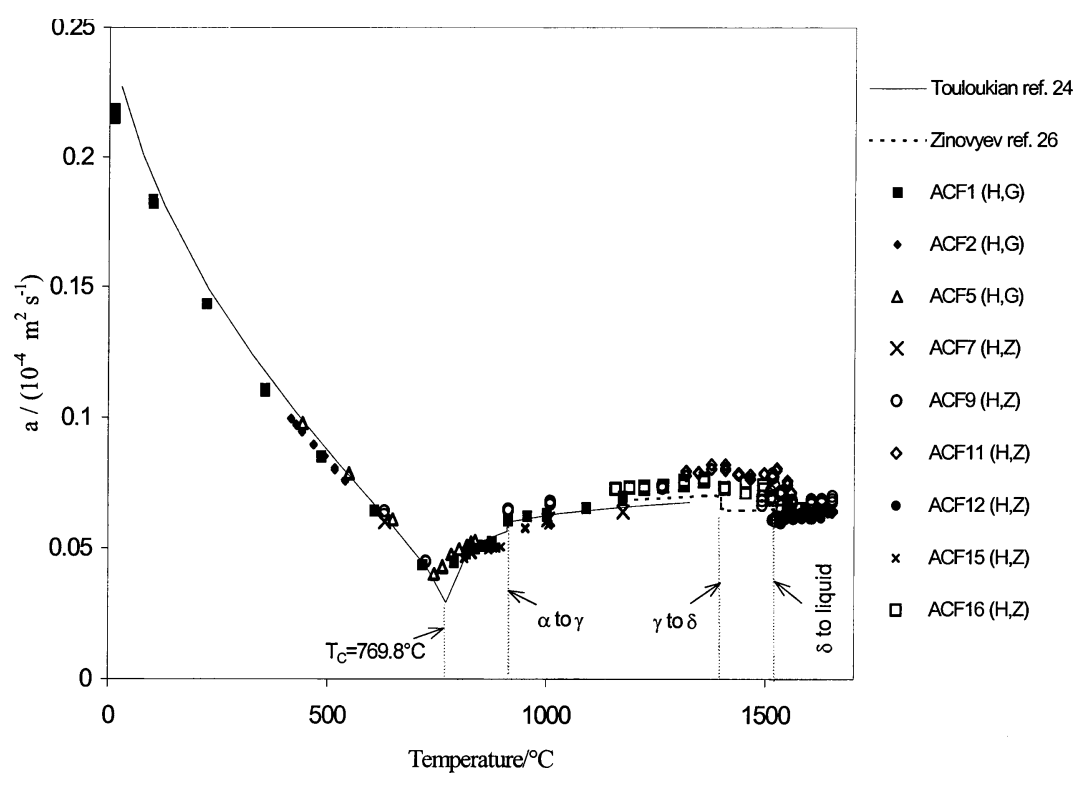

Fig. 4. Change of thermal diffusivity with temperature of iron.

Table 2. Linear expansion data and \%volume change on phase transitions for $\mathrm{Fe}^{27,28)}$

\begin{tabular}{|c|c|c|}
\hline Phase & Expansion Coefficient $/ \mathrm{K}^{-1}$ & Temperature Range ${ }^{/ 0} \mathrm{C}$ \\
\hline$\alpha(\mathrm{BCC})^{26)}$ & $15.5 \times 10^{-6}$ & $20-911$ \\
\hline$\gamma(\mathrm{FCC})^{26)}$ & $23.3 \times 10^{-6}$ & $911-1394$ \\
\hline$\delta(\mathrm{BCC})^{27)}$ & $19.3 \times 10^{-6}$ & $1394-1538$ \\
\hline Phase Change & $\%$ Volume change & Transition Temperature \\
\hline$\alpha$ to $\gamma^{26)}$ & -1.13 & 911 \\
\hline$\gamma$ to $\delta^{27}$ & 0.56 & 1394 \\
\hline
\end{tabular}

Table 3. Recommended values for the thermal diffusivity of pure iron in the $\gamma$ phase. $^{24)}$

\begin{tabular}{|l|c|c|c|c|c|c|}
\hline Temperaure $/{ }^{\circ} \mathrm{C}$ & 27 & 77 & 127 & 227 & 327 & 427 \\
\hline Thermal diffusivity $/ 10^{-4} \mathrm{~m}^{2} \mathrm{~s}^{-1}$ & 0.227 & 0.201 & 0.181 & 0.149 & 0.124 & 0.102 \\
\hline Temperaure $/{ }^{\circ} \mathrm{C}$ & 527 & 627 & 727 & 770 & 827 & 910 \\
\hline Thermal diffusivity $/ 10^{-4} \mathrm{~m}^{2} \mathrm{~s}^{-1}$ & 0.0818 & 0.0630 & 0.0425 & 0.0291 & 0.0512 & 0.0565 \\
\hline
\end{tabular}

ommended thermal diffusivity values and the measured values at temperatures near the Curie temperature $\left(T_{\mathrm{C}}\right)$ and between the $T_{\mathrm{C}}$ and the $\alpha$ to $\gamma$ transformation temperature. It can be seen that around $T_{\mathrm{C}}$ the thermal diffusivity changes considerably and the slope of diffusivity with temperature changes from negative to positive. It may be that the ACF iron's structure may not have been completely at equilibrium. If so, given the changes in thermal diffusivity around the $T_{\mathrm{C}}$ and up to the $\alpha$ to $\gamma$ transformation, this could have a significant impact on the measured thermal diffusivity. As such, the authors prefer to recommend the continued use of the values recommended by Touloukian ${ }^{24)}$ at temperature up to the $\alpha$ to $\gamma$ transformation. The recommended values are given in Table 3.

Above the $\alpha$ to $\gamma$ transformation temperature there were very little data available to Touloukian ${ }^{24)}$ and only one set that went up to approximately $1400^{\circ} \mathrm{C}$. This set of high temperature data were measured by Zinovyev. ${ }^{30)}$ Therefore in the higher temperature regions the only data that can be used to compare with the measurements made in this study are that measured by Zinovyev's group. At high temperatures, in the solid phase, there are no obvious explanation to for the differences between the measured data in this study and those reported by Zinovyev. Where comparisons can be made on other systems both instruments data are in reasonable agreement. ${ }^{2)}$ It may be that sample purity or sample contamination is an issue. Or the differences (scatter) in the data may represent the true uncertainty in the measurement at these temperatures. It is therefore impossible to conclude which data set is most representative of the pure iron. As such the recommended values for thermal diffusivity in the $\gamma$ and $\delta$ phase regions are a mean of the two data sets. Eq. (3) represents the recommended thermal diffusivity values for the $\gamma$ phase, where $T$ is the temperature in Celsius.

$$
a=6 \times 10^{-6}+3.13 \times 10^{-9} \times(T-911)
$$

In the $\delta$ phase region the thermal diffusivity can be represented by the constant $0.07 \times 10^{-4} \mathrm{~m}^{2} \mathrm{~s}^{-1}$.

In the transition from $\delta$ iron to liquid the behaviour of the two sets of data differ considerably. The thermal diffusivity as measured by Zinovyev increases but the data as measured in this study decreases. Generally, a decrease in thermal diffusivity would be expected when a BCC structure (as is iron) melts. ${ }^{2,11)}$ The explanation for this decrease being that there is an increase in disorder associated with the transition, lessening the mean free path associated with energy transfer. ${ }^{2,11)}$ This is supported by electrical conductivity measurements on pure iron, where a decrease in electrical conductivity is associated with the transition from solid to liquid.,11) The results from this study are consistent with such a view.

On the assumption that the liquid Zinovyev data was correct, then what could cause the ACF Fe liquid data to have such low measured thermal diffusivity values. Perhaps it is the zirconia coating on the iron, but from Fig. 3, it can be seen at these temperatures the fine zirconia coating has no effect on the thermal diffusivity of $\mathrm{Cu}$. Perhaps the coating is reacting with the iron or it may be being sub-ducted by the liquid iron. Either has the potential to change the materials thermal properties. To assess whether the zirconia coating was reacting with the sample ACF9 was inspected in the SEM after measurement.

To prepare the sample for SEM analysis the zirconia coated ACF9 sample was sectioned and polished perpen- 


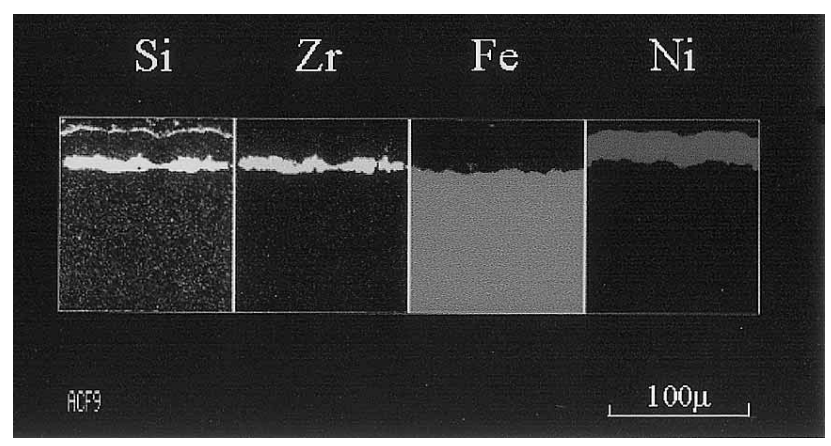

Fig. 5. SEM analysis of the zirconia coated sample, ACF9 after measurement.

dicular to the zirconia coated surface. Figure 5 shows 4 compositional digital maps of the sectioned ACF9 sample. The sample was analysed for $\mathrm{Si}, \mathrm{Zr}, \mathrm{Fe}$ and Ni. The highlighted areas on the digital maps indicate the respective materials are present. From Fig. 5 it can be seen that the coating is continuous and still on the surface of the iron after measurement. Fig. 5, also demonstrates that there is no zirconium, therefore no zirconia, in the bulk of the Fe below the detection limits of the $\operatorname{EDX}(\sim 0.1 \mathrm{wt} \% \mathrm{Zr})$. Indicating that all the zirconia remained on the surface of the sample and was not drawn into or going into solution in the liquid. The Si and Ni shown on the maps are a result of sample preparation for the SEM. Colloidal Si was used to polish the sample and Ni was used to coat sample prior to sectioning and polishing. Fig. 5 indicates that the zirconia coating is unlikely to be the cause of the discrepancy between the different liquid values obtained in this study from that of Zinovyev.

As the liquid thermal diffusivity measurements in this study are more consistent with other properties of liquid iron, ${ }^{2,11)}$ and the fact that the diffusivity has been measured over a wider temperature range (Zinovyev's data only goes up to $30^{\circ} \mathrm{C}$ greater than the melting point), the authors tentatively recommended this studies values for the liquid state. The liquid phase thermal diffusivity values up to a temperature of $1650^{\circ} \mathrm{C}$ can be represented by Eq. (4).

$$
a=6.2 \times 10^{-6}+1.79 \times 10^{-9} \times(T-1538) .
$$

It is clear from Fig. 4 that more work is required to obtain definitive values for the thermal diffusivity of iron at temperatures greater than $1200^{\circ} \mathrm{C}$. The most promising approach would be a round robin involving a number of laboratories measuring the thermal diffusivity of pure iron.

\section{Conclusions}

A technique and measurement practice has been developed that is capable of measuring the thermal diffusivities of iron at high temperatures in both the solid and liquid phases.

Recommended values for the thermal diffusivity of iron have been reported for temperatures between ambient and $1650^{\circ} \mathrm{C}$.

The discrepancies in the high temperature regions $(T>$ $1200^{\circ} \mathrm{C}$ ) of the reported data can only be addressed by further work. This work would be best served by a round robin measurement series where a number of laboratories mea- sure the thermal diffusivity of iron.

\section{Acknowledgements}

This work was undertaken as part of the Materials Measurement Program of the Department of Trade and Industry, United Kingdom. The authors would like to thank Prof. K. C. Mills of Imperial College, London, UK, and the technical support team of Netzsch in Selb, Germany, for their helpful discussions, advice and valuable assistance throughout this study.

\section{REFERENCES}

1) P. N. Quested, K. C. Mills, R. F. Brooks, A. P. Day, R. Taylor and H. Szelagowski: Proc. of the 4th Int. Conf. on Solidification Processing, University of Sheffield, Sheffield, (1997), 143.

2) K. C. Mills, B. J. Monaghan and B. J. Keene: Int. Mater. Rev., 41 (1996), 209.

3) P. R. Austin, H. Nogami and J. Yagi: ISIJ Int., 37 (1997), 748.

4) P. R. Austin, H. Nogami and J. Yagi: ISIJ Int., 38 (1998), 246.

5) G. X.Wang, S. J. Chew, A. B.Yu and P. Zulli: ISIJ Int., 37 (1997), 573.

6) H. Kim, B. Ozturk and R. J. Fruehan: ISIJ Int., 38 (1998), 430

7) S. C. Lee, M. K. Shin, S. Joo and J. K. Yoon: ISIJ Int., 39 (1999), 319.

8) K. Takatani, T. Inada and J. Ujisawa,: ISIJ Int., 39 (1999), 15.

9) Slag Atlas: 2nd ed. Verlag Stahleisen mbH., Düsseldorf, (1995).

10) Handbook of Physico-chemical Properties at High Temperature, ed. by Y. Kawai and Y. Shiraishi, ISIJ, Tokyo, (1988).

11) T. IIda and R. I. L. Guthrie: The Physical Properties of Liquid Metals, Clarendon Press, Oxford, (1993), 226.

12) Compendium of Thermophysical Property Measurement Methods, Vol. 1, Plenium Press, London, (1984), 305.

13) M. Hansen: Constitution of Binary Alloys, McGraw-Hill, London, (1958), 353.

14) S. A. Il'inykh, S. G. Galuts, V. E. Zinovyev and S. P. Bautin: High Temp. (USSR), 22 (1984), 709.

15) L. Dusza: High Temp-High Press., 27 (1995), 467.

16) W. J. Parker, R. J. Jenkins, C. P. Butler and G.L. Abbott: J of Appl. Phys., 32, (1961), 1679.

17) H. Szelagowski and R. Taylor: Proc. of the 4th Asian Thermophysical Properties Conf., ATPC, Tokyo, (1995), 571.

18) H. Szelagowski, R. Taylor, J. D. Hunt and P. N. Quested: Proc. 4th Int. Conf. Solidification Processing, University of Sheffield, Sheffield, (1997), 151.

19) R. Brooks, B. J. Monaghan, A. Barnicoat, A. McCabe, K. C. Mills and P. Quested: Int. J. Thermophys., 17 (1996), 1151.

20) B. J. Monaghan, J. G. J. Neale and L. Chapman: Int. J. Thermophys., 20 (1999), 1051.

21) J. G. Neale: Industrial Training Report, National Physical Laboratory, London, UK, (1997).

22) Y. S. Touloukian, R. W. Powell, C. Y. Ho and M. C. Nicolau: Thermophysical Properties of Matter, Vol. 10, IFI/Plenium, New York, (1973), 51.

23) J. R. Nicholls: Private communication, School of Industrial Manufacturing, Cranfield University, Bedford, UK, (1999).

24) Y. S. Touloukian, R. W. Powell, C. Y. Ho and M. C. Nicolau: Thermophysical Properties of Matter, Vol. 10, IFI/Plenium, New York, (1973), 82.

25) V. E. Zinovyev: Thermophysical Properties of Metals at High Temperatures, Metallurgiya, Moscow, (1989).

26) V. M. Manzhuyev, S. G. Taluts, M. I. Sandakova, B. V. Vlasov and V. E. Zinovyev: Phys. Met. Metallogr., 70 (1990), 195.

27) Y. S. Touloukian, R. K. Kirby, R. E. Taylor and P. D. Desai: Thermophysical Properties of Matter, Vol. 12, IFI/Plenium, New York, (1975), 157.

28) S. Watanabe, Y. Tsu, K. Takano and Y. Shiraishi: J. Jpn. Inst. Met., 45 (1980), 242.

29) Y. S. Touloukian, R. K. Kirby, R. E. Taylor and T. Y. R. Lee: Thermophysical Properties of Matter, Vol. 13, IFI/Plenium, New York, (1977), 176.

30) V. E. Zinovyev, R. P. Krentis and P. V. Geld: Phys. Met. Metallogr., 26 (1968), 167. 